\title{
Metabolic Response to a Ketogenic Breakfast in the Healthy Elderly
}

Erika Freemantle, Milène Vandal, Jennifer Tremblay-Mercier, Mélanie Plourde, Judes Poirier and Stephen C. Cunnane

\section{Research Center on Aging}

Health and Social Services Center - Sherbrooke University Geriatrics Institute, and Departments of Medicine and Physiology and Biophysics, Université de Sherbrooke

$$
\text { (EF, MV, JTM, MP, SCC) }
$$

Departments of Medicine and Psychiatry, McGill University (JP)

Please address correspondence to Stephen C. Cunnane

Email: Stephen.Cunnane@usherbrooke.ca, telephone: (819) 821-1170 ext. 45132, fax: (819) 821-7141, 1036 Belvédère S., Sherbrooke, QC, Canada, J1H 4C4. Funding for this project was provided by the Natural Science and Engineering Research Council of Canada, Canadian Foundation for Innovation, Canada Research Chairs Secretariat (SCC), Université de Sherbrooke, and the Research Center on Aging.

Running Head: Metabolic response to a ketogenic breakfast in the healthy elderly 


\section{Abstract}

Objective: To determine whether the metabolism of glucose or ketones differs in the healthy elderly compared to young or middle-aged adults during mild, short-term ketosis induced by a ketogenic breakfast.

Design and participants: Healthy subjects in three age groups $(23 \pm 1,50 \pm 1$ and $76 \pm 2$ y old) were given a ketogenic meal and plasma $\beta$-hydroxybutyrate, glucose, insulin, triacylglycerols, total cholesterol, non-esterified fatty acids and breath acetone were measured over the subsequent $6 \mathrm{~h}$. Each subject completed the protocol twice in order to determine the oxidation of a tracer dose of both carbon-13 $\left({ }^{13} \mathrm{C}\right)$ glucose and ${ }^{13} \mathrm{C}-\beta$-hydroxybutyrate. The tracers were given separately in random order. Apolipoprotein E genotype was also determined in all subjects.

Results: Plasma glucose decreased and $\beta$-hydroxybutyrate, acetone and insulin increased similarly over $6 \mathrm{~h}$ in all three groups after the ketogenic meal. There was no significant change in cholesterol, triacylglycerols or non-esterified fatty acids over the 6 h. ${ }^{13} \mathrm{C}$-glucose and ${ }^{13} \mathrm{C}-\beta$-hydroxybutyrate oxidation peaked at $2-3 \mathrm{~h}$ post-dose for all age groups. Cumulative ${ }^{13} \mathrm{C}$-glucose oxidation over $24 \mathrm{~h}$ was significantly higher in the elderly but only versus the middle-aged group. There was no difference in cumulative ${ }^{13} \mathrm{C}-\beta$-hydroxybutyrate oxidation between the three groups. Apolipoprotein $E(\varepsilon 4)$ was associated with elevated fasting cholesterol but was unrelated to the other plasma metabolites.

Conclusion: Elderly people in relatively good health have a similar capacity to produce ketones and to oxidize ${ }^{13} \mathrm{C}-\beta$-hydroxybutyrate as middle-aged or young adults, but oxidize ${ }^{13} \mathrm{C}$-glucose a little more rapidly than healthy middle-aged adults. Keywords: ketones, glucose, healthy elderly, ${ }^{13} \mathrm{C}$ stable isotope tracers. 


\section{Introduction}

In humans, glucose is the brain's primary energy substrate and ketone bodies (ketones) are it's primary replacement fuel during fasting or low carbohydrate intake (1). Ketones refers collectively to three molecules: acetoacetate (AcAc), $\beta$ hydroxybutyrate $(\beta-\mathrm{OHB})$, and acetone (2). During ketogenesis, $A c A c$ is formed first and is the only ketone metabolized by the tricarboxylic acid cycle as an energy substrate. After being converted back to AcAc by $\beta$-OHB dehydrogenase, $\beta$-OHB can also serve as an energy substrate (3). Acetone is produced by decarboxylation of AcAc and is exhaled in the breath in proportion to plasma ketone concentrations (2). Impaired availability of energy substrates to the brain may be implicated in the progression towards Alzheimer's disease $(4,5)$. Raising blood ketones with a ketogenic meal shows preliminary potential to alleviate some features of the cognitive deficit in Alzheimer's disease (6). Given this potentially important clinical application, but the relative scarcity of information about how energy substrates are utilized during healthy aging, i.e. during aging minimally confounded by symptomatic degenerative disease, our primary objective was to evaluate glucose and ketone utilization in the healthy elderly compared to young and middle-aged adults. Insulin inhibits ketone production so to achieve short-term ketogenesis subjects were given a very low carbohydrate breakfast composed of medium chain triacylglycerol (MCT), heavy cream, protein powder and water. MCT efficiently induce mild to moderate ketosis in humans (7) because they are rapidly absorbed and pass directly via the hepatic portal venous circulation to the liver where they are $\beta$-oxidized with some of the resulting acetyl CoA being captured in ketones. MCT do not require a carnitine-dependent transport system to enter the inner mitochondrial space, and are thus more readily available for oxidation and at a lower energetic cost than long 
52 chain triacylglycerol (LCT) (8). Although the present study was not designed or

53 powered for analysis of the effect of genotype, apolipoprotein E genotype of our

54 subjects was determined since it affects both post-prandial fat metabolism (9) and 55 risk of Alzheimer's disease $(10,11)$. 


\section{Materials and Methods}

Subjects: Subjects were recruited in three age groups: 18-25 y old (young: Y), 40-55 y old (middle-aged: M), and 70-85 y old (elderly: E). This distribution maintained a minimum 15 y gap between age groups and also avoided the increasing impact of frailty beyond 85 y old (12). All subjects were non-smokers and determined to be in relatively good health by a medical evaluation and blood screening done after a $12 \mathrm{~h}$ overnight fast. Fasting glucose and hemoglobin $\mathrm{HbA}_{1 \mathrm{c}}$ were used to rule out the presence of overt diabetes. A complete blood cell count was used for blood disorders; electrolyte profile, AST and ALT for renal and liver function; HDL and LDL cholesterol, triglycerides; albumin for nutritional status; C-reactive protein as a marker of inflammatory processes; and TSH for thyroid function. Anthropometric parameters such as height, weight, body mass index (BMI), and fasting plasma metabolites did not differ significantly between age groups (Table 1). Approval for the study was obtained from the Research Ethics Committee of the Health and Social Services Center - Sherbrooke University Geriatrics Institute, which oversees all human research done at the Research Center on Aging.

4

Tracer protocol and sample collection: Subjects arrived at 7:30 a.m. after having fasted overnight for $12 \mathrm{~h}$. An intravenous forearm catheter was installed and baseline blood samples taken. The catheter was kept patent by flushing hourly with nonheparinized saline. The stable isotope tracer was then consumed $\left({ }^{13} \mathrm{C}\right.$-glucose or $\left.{ }^{13} \mathrm{C}-\beta-\mathrm{OHB}\right)$, followed immediately by the ketogenic breakfast drink, which was consumed within approximately 30 mins. After consuming the ketogenic breakfast, blood samples were taken hourly over 6 h using a 5 ml latex-free syringe (Becton Dickinson, Franklin Lakes, NJ) and transferred immediately to a $5 \mathrm{~mL} \mathrm{~K}_{2}$-EDTA- 
coated tube (Becton Dickinson, Franklin Lakes, NJ). Tubes were stored on ice at $4^{\circ} \mathrm{C}$ until the conclusion of the study period at which point they were all centrifuged at $3500 \mathrm{rpm}$ for $18 \mathrm{~min}$ at $4^{\circ} \mathrm{C}$. The separated plasma was stored at $-20^{\circ} \mathrm{C}$ until further analyzed. During the $6 \mathrm{~h}$ study period, water was available ad libitum and subjects were asked to remain in a resting position with short walks.

Each subject participated in two identical metabolic study days, one to test ${ }^{13} \mathrm{C}$-glucose metabolism and the other to test ${ }^{13} \mathrm{C}-\beta-\mathrm{OHB}$ metabolism. The tracers were $\mathrm{U}-{ }^{13} \mathrm{C}_{6} \mathrm{D}$-glucose or $2,4-{ }^{13} \mathrm{C}_{2}$ sodium D-3-hydroxybutyrate (50 mg each; Cambridge Isotope Laboratories, Andover, MA) were consumed in $15 \mathrm{~mL}$ nanopure water and in randomized order. The two study days were separated by at least one but not more than three weeks. Breath samples for ${ }^{13} \mathrm{CO}_{2}$ and acetone analysis were collected in triplicate at baseline and every 30 min afterwards using a breath collection device (Easysampler, Quintron Instrument Company, Milwaukee, WI) and $10 \mathrm{~mL}$ evacuated glass tubes (Exetainer, Labco Ltd, Buckinghamshire, UK). The first $\sim 150 \mathrm{~mL}$ of exhaled air is dead space (13), so to collect a true alveolar breath sample, the subjects exhaled for $3 \mathrm{sec}$ before breath sample collection. For acetone analysis, $1 \mathrm{~mL}$ of breath was transferred from one of the three Exetainer tubes to a glass gas-tight syringe (Hamilton Company, Reno, NV).

Ketogenic breakfast drink: The ketogenic breakfast drink consisted of a blend of MCT (Mead Johnson, Ottawa, ONT, CA), 35\% heavy cream (Québon Ultra Crème, Longueuil, QC, CA), raspberry-flavored milk protein powder (Davisco Foods International, Inc., Eden Prairie, MN, courtesy of Agropur Cooperative, Granby, QC, CA) and water (Table 2). The fatty acid composition of the ketogenic breakfast is shown in Table 3. This ketogenic breakfast was designed to give a ratio of total fat to 
107 protein plus carbohydrate of $4.5: 1$, which is sufficient to induce mild, short-term

108 ketosis in young adults (2). The total carbohydrate content of the drink was limited to

109 the carbohydrate already in the cream (3.2\%). Total protein content was calculated to

110 be $1 / 3$ of the subject's daily protein requirement as determined by the Harris-Benedict

111 equation and the Canada Food Guide (Health Canada, Ottawa, ON, CA). Total fat

112 was then adjusted to be equivalent to 4.5 times the protein plus carbohydrate

113 content. Subjects received an average of $1104 \mathrm{kCal}, 90 \%$ of which was fat. In the

114 breakfast drink, the amount of total fat $(\mathrm{g}), \operatorname{MCT}(\mathrm{g})$, fat $/$ body weight $(\mathrm{g} / \mathrm{kg})$, or fat/BMI

$115\left(\mathrm{~g} / \mathrm{kg} / \mathrm{m}^{2}\right)$ did not differ significantly across the three study groups.

117 Isotope ratio mass spectrometry: Enrichment of ${ }^{13} \mathrm{C}$ in breath $\mathrm{CO}_{2}$ following the

118 ingestion of the ${ }^{13} \mathrm{C}$ tracer was analyzed by isotope ratio mass spectrometry (Europa

119 20-20, Sercon Ltd, Crewe, Cheshire, UK) as previously described (14). $5 \% \mathrm{CO}_{2} / \mathrm{N}_{2}$

120 was the reference gas and He was the carrier gas (Praxair Canada Inc. Mississauga,

$121 \mathrm{ON}$, Canada). Atom percent (AP) is the relative abundance of ${ }^{13} \mathrm{C}$ in the sample

122 calculated by the following equation:

$123 \quad(1)$

$125{ }^{13} \mathrm{C}$ data in delta notation $(\delta)$ is the ratio of ${ }^{13} \mathrm{C}$ to ${ }^{12} \mathrm{C}$ calibrated against the reference

126 gas and the international standard, Peedee Belemnite (15). The percent dose

127 recovered (PDR) of the tracer administered to the subjects was calculated as in

128 equation (2),

$129 \quad(2)$

$$
A P=\frac{100}{1 /\left[(\delta / 1000+1){ }^{13} C_{\text {ref }}+1\right]}
$$


131 In which atom percent excess (APE) is calculated using of the value obtained in

132 equation (1) for time t minus the value obtained at time 0 . Taking into account the

133 chemical purity, the isotopic enrichment of the tracer, and the natural abundance of

$134{ }^{13} \mathrm{C}$, the quantity of ${ }^{13} \mathrm{C}$ excreted on breath (mmol) was calculated as shown in

135 equation (3):

136 (3) $\mathrm{mmol}^{13} \mathrm{C}=\ldots$ mg tracer $\times$ chemical purity $\times\left(\left[99 \% \#^{13} \mathrm{C}\right]+[1 \%\right.$ total \# C] $)$ molecular weight

138 The chemical purity of both tracers was $98 \%$ and their isotopic purity was $99 \%$. The

$139 \mathrm{CO}_{2}$ production constant of $300 \mathrm{mmol} / \mathrm{h}$ was used as determined by Schofield (16)

140 and previously validated for healthy adults (17). $V_{\mathrm{CO} 2}$ was then calculated by

141 multiplying the $\mathrm{CO}_{2}$ production constant $(300 \mathrm{mmol} / \mathrm{h})$ by body surface area,

142 calculated according to Gehan and George (18).

143

144 Gas chromatographic analysis of acetone: Triplicate $0.3 \mathrm{ml}$ samples of breath

145 collected into gastight syringes were injected directly on to a capillary gas

146 chromatograph equipped with a flame ionization detector (Agilent model 6890, Palo

147 Alto, CA) and 30 m DB-WAX column (0.25 mm i.d.; Agilent J\&W Scientific Santa

148 Clara, CA). The temperature of the oven was set at $30^{\circ} \mathrm{C}$ and held for one minute

149 and then increased at a rate of $5^{\circ} \mathrm{C} / \mathrm{min}$ to $60^{\circ} \mathrm{C}$ where it was held for $2 \mathrm{~min}$. The

150 carrier gas was $\mathrm{He}$ and the flow rate was $7 \mathrm{~mL} / \mathrm{min}$. The injector temperature was

$151150^{\circ} \mathrm{C}$ and the detector temperature was $250^{\circ} \mathrm{C}$. Acetone peak areas were calibrated

152 against an aqueous acetone standard. A $0.2 \mathrm{~mL}$ of the aqueous standard was then

153 injected into the gas chromatograph. 
155 Other analyses: Plasma glucose, $\beta-\mathrm{OHB}$, cholesterol, triacylglycerols (TG), and non-

156

157

158

159

160

161

162

163

164

165

166

167

168

169

170

171

172

173

174

175

176

177 esterified fatty acids (NEFA) were measured by colorimetric assay using an automated clinical chemistry analyzer (Dimension XPand Plus, Dade Behring Inc., Newark, DE) and commercially available reagent kits from the same company, except for $\beta$-OHB (RX Daytona kit; Randox Laboratories Ltd., Antrim, UK), and NEFA (Wako Diagnostics, Richmond, VA). Insulin was analyzed by ELISA (Mercodia, Upssala, Sweden) and a microplate reader (model 3550, BioRad, Hercules, CA). ApoE genotype was analyzed at the McGill University Center for Studies in Aging (19).

Fatty acid composition of the ketogenic breakfast, MCT, and cream was analyzed by extraction of the total lipids into $2: 1$ chloroform/methanol with $0.02 \%$ $\mathrm{BHT}$, using triheptadecanoin as the internal standard (20). The total lipids were then saponified with $1 \mathrm{M}$ methanolic $\mathrm{KOH}$ followed by derivitization of the fatty acids to fatty acid methyl esters using $14 \% \mathrm{BF}_{3}$ methanol. Fatty acid methyl esters were analyzed using a gas chromatograph (Agilent model 6890) equipped with a $50 \mathrm{~m}$ BPX-70 fused capillary column (0.25 mm i.d. x $0.25 \mu \mathrm{m}$ film thickness; J\&W Scientific, Folsom, CA). Splitless injection and flame ionization detection were performed at $250^{\circ} \mathrm{C}$. The oven temperature program was $50^{\circ} \mathrm{C}$ for $2 \mathrm{~min}$, increasing to $170^{\circ} \mathrm{C}$ at a rate of $20^{\circ} \mathrm{C} / \mathrm{min}$, held for $15 \mathrm{~min}$, increased to $210^{\circ} \mathrm{C}$ at a rate of $5^{\circ} \mathrm{C} / \mathrm{min}$ and held there for $7 \mathrm{~min}$. The inlet pressure of the carrier gas $(\mathrm{He})$ was $233 \mathrm{kPa}$ at $50^{\circ} \mathrm{C}$. The identity of individual fatty acids was determined by comparing retention times with standard mixtures of fatty acids (NuChek 68A, 411, 455; NuChek Prep, Inc., Elysian, MN) and a custom mixture of saturated fatty acid standards. 
179 Statistical analysis: Results are given as mean \pm SEM. Comparisons during the

180 metabolic study period are shown from baseline (time $0 \mathrm{~h} ; \mathrm{T}_{0}$ ) up to $6 \mathrm{~h}$ later $\left(\mathrm{T}_{6}\right)$, and

181 again $24 \mathrm{~h}$ later $\left(\mathrm{T}_{24}\right)$ for tracer oxidation. To determine if tracer oxidation differed over

182 time or between age groups, a repeated measures two-way ANOVA was performed

183 followed by a Bonferroni post-hoc test to determine where significant differences

184 existed. The Pearson test was used to test the significance of correlations between

185 plasma and breath metabolites. Ketogenic breakfast composition was analyzed by

186 one-way ANOVA. Statistical analysis of tracer oxidation data, differences in ketogenic

187 meals composition and fatty acid profile between groups, and correlations were

188 performed with Prism software (version 4.0, GraphPad Prism, San Diego, CA). An

189 independent variables ANOVA test for time and age was performed to determine if

190 any of the plasma metabolites differed between age groups or by ApoE $\varepsilon 4$ genotype.

191 Statistical analysis of plasma metabolites was performed with SPSS software

192 (version 12.0, SPSS Inc, Chicago, IL). Significance was set at $\mathrm{p} \leq 0.05$.

193 
195

196

197

198

199

200

201

202

203

204

205

206

207

208

209

210

211

212

213

214

215

216

217

218

219

\section{Results}

Plasma and breath metabolites: From baseline $\left(\mathrm{T}_{0}\right)$ to $6 \mathrm{~h}$ after taking the ketogenic breakfast drink and tracer $\left(T_{6}\right)$, plasma glucose was mostly stable in all three groups but between $T_{3}$ and $T_{6}$, glucose was $12 \%$ higher in the $E$ compared to the $Y$ group $\left(p<0.05 ;\right.$ Figure 1). In all three groups, plasma insulin peaked at $90-105 \mathrm{pmol} / \mathrm{L}$ at $\mathrm{T}_{1}$ to $T_{2}$. Except at $T_{2}$ in the $M$ group, the $M$ and $E$ groups had a similar post-prandial insulin response to the $Y$ group. Between $T_{0}$ and $T_{6}$ and in all three groups, plasma $\beta$ OHB rose from $\sim 0.1$ to $\sim 1.3 \mathrm{mmol} / \mathrm{L}$ and breath acetone rose from $\sim 13$ to $\sim 87 \mathrm{nmol} / \mathrm{L}$ (Figure 1). Breath acetone was higher at $T_{6}$ in the $M$ and $E$ groups versus the $Y$ group. For all subjects, there was a significant positive correlation between plasma $\beta$ $\mathrm{OHB}$ and breath acetone at $\mathrm{T}_{0}$ and $\mathrm{T}_{6}$ (Figure 2).

${ }^{13} \mathrm{C}$ Tracer oxidation: In all subjects and with both tracers, ${ }^{13} \mathrm{CO}_{2}$ excretion on breath peaked at 2-4 h post-dose and returned close to baseline within $24 \mathrm{~h}$ of tracer administration. In all three age groups, ${ }^{13} \mathrm{C}$-glucose oxidation peaked at 6.4 to $7.4 \%$ dose/h between $\mathrm{T}_{2.5}$ and $\mathrm{T}_{3}$ (Figure 3). At $\mathrm{T}_{4.5}, \mathrm{~T}_{5}$ and $\mathrm{T}_{6},{ }^{13} \mathrm{C}$ glucose oxidation was significantly higher in the $\mathrm{E}$ compared to the $\mathrm{M}$ group. Cumulative ${ }^{13} \mathrm{C}$ glucose oxidation $24 \mathrm{~h}$ after dosing was $72 \%, 62 \%$, and $77 \%$ of dose for $\mathrm{Y}, \mathrm{M}$ and $\mathrm{E}$ subjects, respectively (Figure 3). From $\mathrm{T}_{5}$ to $\mathrm{T}_{24}$, cumulative oxidation of ${ }^{13} \mathrm{C}$ glucose was significantly higher in the $E$ versus $M$ group $(P<0.05)$, but not compared to the $Y$ group. In all three groups, ${ }^{13} \mathrm{C} \beta$-OHB oxidation peaked at $\sim 7.5 \%$ dose $/ \mathrm{h}$ at $\mathrm{T}_{2}$.

Cumulative $24 \mathrm{~h}{ }^{13} \mathrm{C} \beta$-OHB oxidation was $65 \%, 74 \%$, and $77 \%$ of the dose administered in $\mathrm{Y}, \mathrm{M}$ and $\mathrm{E}$ subjects, respectively, with no significant differences between groups (Figure 3). 
220 Other measurements: There was no significant effect of the ketogenic breakfast on

221 plasma TG, NEFA, or total cholesterol over the $6 \mathrm{~h}$ study period (Figure 4). However, 222 from $T_{3}$ to $T_{6}$, plasma $T G$ and total cholesterol were significantly elevated in the $E$ 223 group compared to the $Y$ group.

$224 \quad$ Genotype distribution could only be determined for 27 of the 31 subjects 225 (Table 4). For statistical comparisons, genotypes were grouped according to 226 presence or not of the ApoE $\varepsilon 4$ allele. As expected, $\varepsilon 4$ carriers had significantly 227 elevated plasma cholesterol, but had no significant differences in other metabolites 228 (data not shown). 


\section{Discussion}

Overall, we found that for $6 \mathrm{~h}$ after consuming a ketogenic breakfast drink, elderly, middle-aged and young adults in good health had a comparable changes in plasma $\beta-\mathrm{OHB}$ and breath acetone. To our knowledge, previously published studies of ketone levels in the elderly have not reported their production after a ketogenic meal. For instance, higher plasma $\beta$-OHB was reported for the elderly, but only after an $18 \mathrm{~h}$ fast (21). Our study confirms the previously reported short term ketogenic effect of a very low carbohydrate breakfast (2), and shows that the healthy elderly achieve a level of ketosis (plasma $\beta-\mathrm{OHB}$ and breath acetone) and $24 \mathrm{~h}$ oxidation of $\beta-\mathrm{OHB}$ that is equivalent to or slightly above what is observed in healthy young and middle-aged subjects. In the absence of differences in plasma $\beta-\mathrm{OHB}$ or $\beta-\mathrm{OHB}$ oxidation, whether the doubling of breath acetone at the end of the $6 \mathrm{~h}$ metabolic study day is physiologically meaningful remains to be determined.

Our elderly group had statistically significant but very modest differences in glucose metabolism compared to the middle-aged our young adults. Although fasting glucose was not statistically different between the three groups, plasma glucose (but not insulin) was statistically higher in the elderly towards the end of the metabolic study period. Cumulative glucose oxidation over $24 \mathrm{~h}$ was $24 \%$ higher in the elderly but only versus the middle-aged group; the glucose oxidation did not differ significantly between the elderly and young groups. Without further experimentation, these data are difficult to interpret because although higher plasma glucose could be due to various mechanisms related to emerging insulin resistance, one would not expect a concomitant rise in glucose oxidation (Figure 3) if, in fact, glucose metabolism was impaired. 
Statistically significant differences between age groups in cholesterol and TG also emerged 3-6 $\mathrm{h}$ after taking the breakfast meal. Issa et al. have also reported somewhat slower TG clearance after consuming a meal containing $40 \mathrm{~g}$ of fat (22). Several studies have suggested that slower post-prandial clearance of an oral fat load may contribute to aging-associated pathology such as coronary heart disease $(23,24)$ and may be influenced by declining insulin sensitivity $(25-27)$. Postprandially, the plasma cholesterol response of both the $M$ and the $E$ groups was elevated compared to the $Y$ group. This could be attributed to the presence of four subjects in the $\mathrm{M}$ group who were ApoE $\varepsilon 4$ carriers, as this polymorphism is known to elevate cholesterol levels (28). In fact, when the $\varepsilon 4$ carriers were removed, cholesterol data for the $\mathrm{M}$ group fell between the $\mathrm{Y}$ and $\mathrm{E}$ groups (data not shown). Although baseline plasma TG was non-significantly higher in the elderly, none of the subjects showed a significant post-prandial TG response between $T_{0}-T_{6}$. Given that the ketogenic breakfast contained approximately 50\% LCT (Table 3), a post-prandial increase in plasma TG would have been anticipated. Seaton et al. found that in comparison with LCT, there was no significant change in plasma TG and even a slight decrease during the first hour after a single dose of $48 \mathrm{~g}$ of MCT

271 (29). Hill et al. observed an increase in fasting TG but no change over $6 \mathrm{~h}$ after giving 272 a single dose of MCT following a 6 day diet in which MCT represented $40 \%$ of daily 273 energy requirements (30). MCT are clearly absorbed differently from LCT but, in our 274 study, it is still not clear whether MCT or the low carbohydrate content of the meal 275 could have suppressed the plasma TG response to the LCT in the cream. By design, the ketogenic breakfast given to our subjects was not strictly 277 isoenergetic across groups. Rather, using the Harris-Benedict equation, the energy 278 content of the ketogenic breakfast was calculated in terms of percentage of basal 
279 energy needs, which takes into account several parameters including gender, age, 280 and anthropometric parameters. Other methods to match meals across groups with 281 different anthropometry include normalizing to only one parameter such as fat in the 282 meal to body weight, BMI, or hip-to-waist ratio. Recent studies suggest a stronger 283 relation of parameters such as insulin resistance to body fat mass rather than to age 284 itself $(31,32)$. As such, determining \% body fat distribution might have helped us 285 more accurately compare subjects. Regardless, neither the calculated values for 286 basal energy expenditure nor the total fat content $(\mathrm{g})$, MCT content $(\mathrm{g})$, fat 287 content/body weight $(\mathrm{g} / \mathrm{kg})$, or fat content/BMI $\left(\mathrm{g} / \mathrm{kg} / \mathrm{m}^{2}\right)$ differed significantly between 288 the three age groups $(P>0.05)$.

289 Our main objective was to assess the short-term ketone response to a 290 ketogenic breakfast during healthy aging and we conclude that the ability to produce 291 ketones appears to be fully functional during healthy aging. Hence, these results 292 support emerging strategies aiming to use physiological levels of ketones to correct 293 or bypass deteriorating brain glucose uptake in the elderly. 
295 Acknowledgements

296 Funding for this project was provided by the Natural Science and Engineering

297 Research Council of Canada, Canadian Foundation for Innovation, Canada

298 Research Chairs Secretariat (SCC), Université de Sherbrooke, the Department of

299 Medicine, Université de Sherbrooke for a post-doctoral fellowship to MP, and the

300 Research Center on Aging. The author would like to thank Mélanie Fortier, Julie

301 Desgagné, Doris Dea, and Mary Ann Ryan for their excellent technical assistance. 


\section{Table 1}

Anthropometric characteristics and fasting plasma constituents.

$\begin{array}{ccc}\text { Young } & \text { Middle-aged } & \text { Elderly } \\ (n=11) & (n=12) & (n=9)\end{array}$

Anthropometry:

Age (y)

$23 \pm 1$

$50 \pm 1$

$76 \pm 2$

Height ( $m)$

$1.74 \pm 0.03$

$1.65 \pm 0.03$

$1.67 \pm 0.08$

Weight $(\mathrm{kg})$

$77.4 \pm 4.9$

$74.2 \pm 4.6$

$72.3 \pm 3.7$

$\operatorname{BMI}\left(\mathrm{kg} / \mathrm{m}^{2}\right)$

$25.3 \pm 1.1$

$27.2 \pm 1.6$

$25.7 \pm 1.3$

Fasting plasma measures:

$\beta$-Hydroxybutyrate (mmol/L)

$0.07 \pm 0.10$

$0.09 \pm 0.13$

$0.07 \pm 0.04$

Glucose (mmol/L)

$5.4 \pm 0.6$

$5.3 \pm 0.4$

$5.7 \pm 0.7$

Insulin (mUI/L)

$6.8 \pm 4.4$

$4.5 \pm 3.9$

$4.0 \pm 2.6$

Triacylglycerol (mmol/L)

$0.9 \pm 0.3$

$1.1 \pm 0.5$

$1.5 \pm 0.5$

Non-esterified fatty acids (mmol/L)

$0.6 \pm 0.3$

$0.5 \pm 0.1$

$0.6 \pm 0.2$

Cholesterol (mmol/L)

$4.2 \pm 0.4$

$5.3 \pm 1.1$

$5.3 \pm 0.7$

Mean \pm SEM. No significant difference in any parameter except age $(P<0.0001)$. 
Table 2

Ketogenic breakfast meal composition ${ }^{1}$

(g) (\%)

\begin{tabular}{lcc}
\hline Components: & \\
protein powder & $25 \pm 1$ & 10 \\
cream & $100 \pm 0$ & 41 \\
medium chain triacylglycerol & $71 \pm 4$ & 29 \\
water & $46 \pm 2$ & 20 \\
Macronutrients: & & \\
protein & $25 \pm 1$ & 18 \\
carbohydrate & $3 \pm 0$ & 2 \\
fat & $110 \pm 4$ & 80 \\
\hline \hline
\end{tabular}

${ }^{1}$ Calculated to give a ratio of 4.5:1 parts fat to protein plus carbohydrates based on $1 / 3$ of the subject's daily protein requirements according to basal energy expenditure. Meal components and macronutrients are given as mean $\pm \operatorname{SEM}(n=32)$. Meal content did not differ significantly between age groups. 


\section{Table 3}

Fatty acid composition (\%) of the ketogenic breakfast and its fat components ${ }^{1}$

\begin{tabular}{lccc} 
& Breakfast & MCT & Cream \\
& $\mathrm{n}=32$ & $\mathrm{n}=3$ & $\mathrm{n}=3$ \\
\hline $8: 0$ & $14.4 \pm 1.5$ & $39.8 \pm 0.4$ & $\mathrm{~N} / \mathrm{D}$ \\
$10: 0$ & $31.3 \pm 0.8$ & $58.6 \pm 0.3$ & $5.9 \pm 0.1$ \\
$12: 0$ & $4.0 \pm 0.1$ & $1.6 \pm 0.1$ & $8.9 \pm 0.1$ \\
$14: 0$ & $9.8 \pm 0.4$ & $\mathrm{~N} / \mathrm{D}$ & $21.9 \pm 0.2$ \\
$16: 0$ & $20.4 \pm 0.7$ & $\mathrm{~N} / \mathrm{D}$ & $31.9 \pm 0.1$ \\
$18: 0$ & $4.9 \pm 0.3$ & $\mathrm{~N} / \mathrm{D}$ & $6.5 \pm 0.2$ \\
Total Saturates & $\mathbf{8 4 . 7} \pm \mathbf{1 . 3}$ & $\mathbf{1 0 0 . 0} \pm \mathbf{0}$ & $\mathbf{7 5 . 0} \pm \mathbf{0 . 2}$ \\
14:1n-5 & $1.3 \pm 0.6$ & $\mathrm{~N} / \mathrm{D}$ & $2.3 \pm 0.0$ \\
16:1n-7 & $1.0 \pm 0.1$ & $\mathrm{~N} / \mathrm{D}$ & $2.4 \pm 0.1$ \\
18:1n-9 & $11.0 \pm 0.6$ & $\mathrm{~N} / \mathrm{D}$ & $18.1 \pm 0.2$ \\
Total Monounsaturates & $\mathbf{1 4 . 0 \pm 0 . 6}$ & $\mathrm{N} / \mathrm{D}$ & $\mathbf{2 2 . 8} \pm \mathbf{0 . 2}$ \\
18:2n-6 & $1.1 \pm 0.2$ & $\mathrm{~N} / \mathrm{D}$ & $2.3 \pm 0.1$ \\
Total Polyunsaturates & $\mathbf{1 . 1} \pm \mathbf{0 . 2}$ & $\mathrm{N} / \mathbf{D}$ & $\mathbf{2 . 3} \pm \mathbf{0 . 1}$ \\
\hline \hline
\end{tabular}

${ }^{1}$ Meal composition, given as mean \pm SEM. Meal energy content did not differ significantly between age groups. $N / D=$ not detected. 
Table 4.

Apolipoprotein E genotype of the subjects.

\begin{tabular}{lccccccc} 
& $2 / 2$ & $3 / 2$ & $3 / 3$ & $4 / 3$ & $4 / 4$ & $4 / 2$ & total \\
\hline Young & 0 & 4 & 5 & 0 & 0 & 0 & 9 \\
Middle-aged & 1 & 3 & 3 & 3 & 0 & 1 & 11 \\
Elderly & 0 & 0 & 6 & 1 & 0 & 0 & 7 \\
\% Frequency & 4 & 26 & 51 & 15 & 0 & 4 & 100 \\
\hline \hline
\end{tabular}

Apolipoprotein $E$ genotype is shown as the combinations of Apolipoprotein $E \varepsilon 2,3$, or 4 variant alleles. 

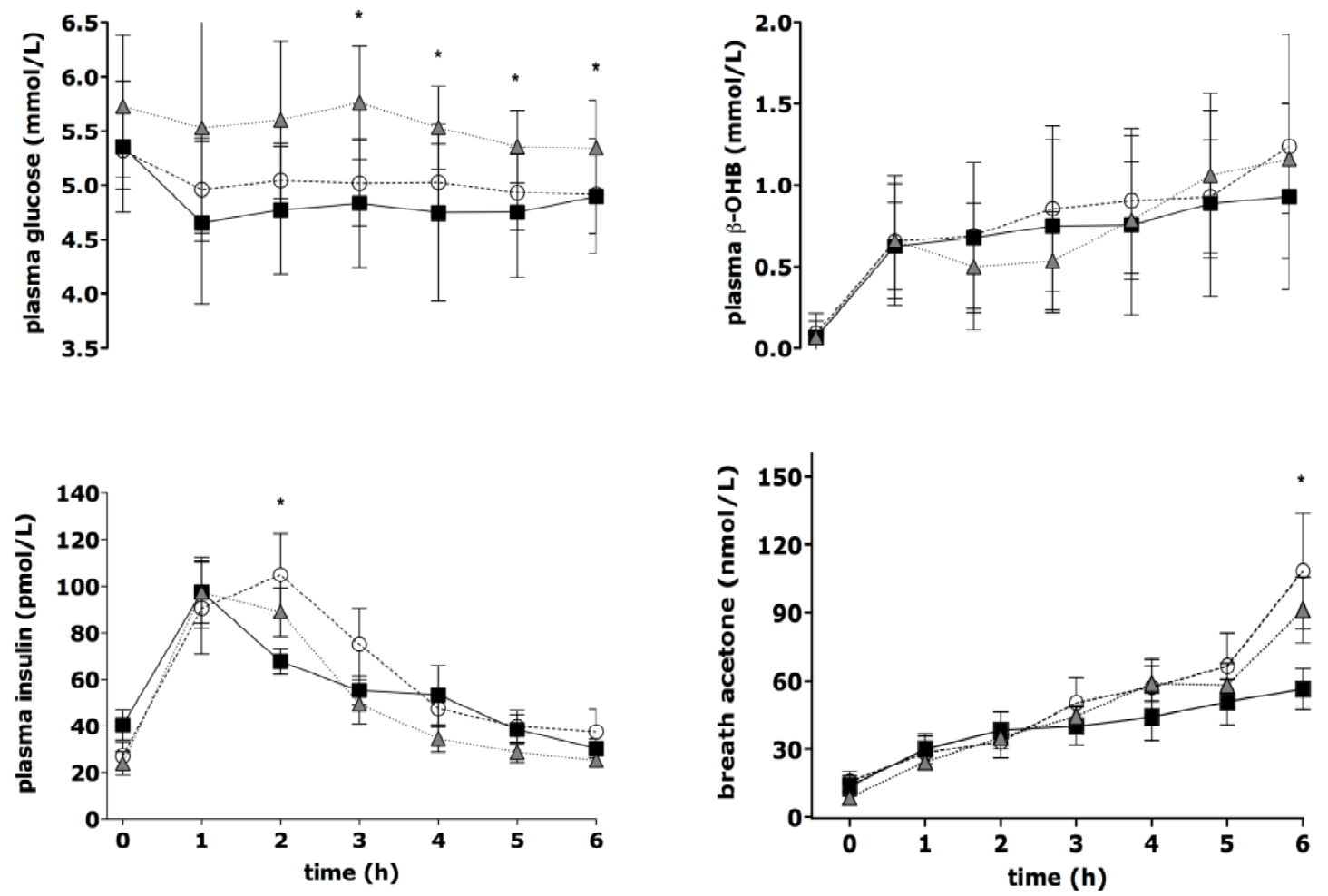

Figure 1. 


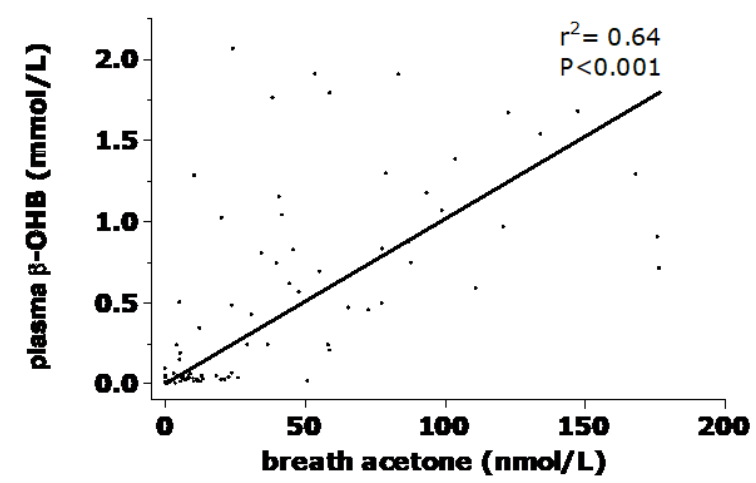

Figure 2. 

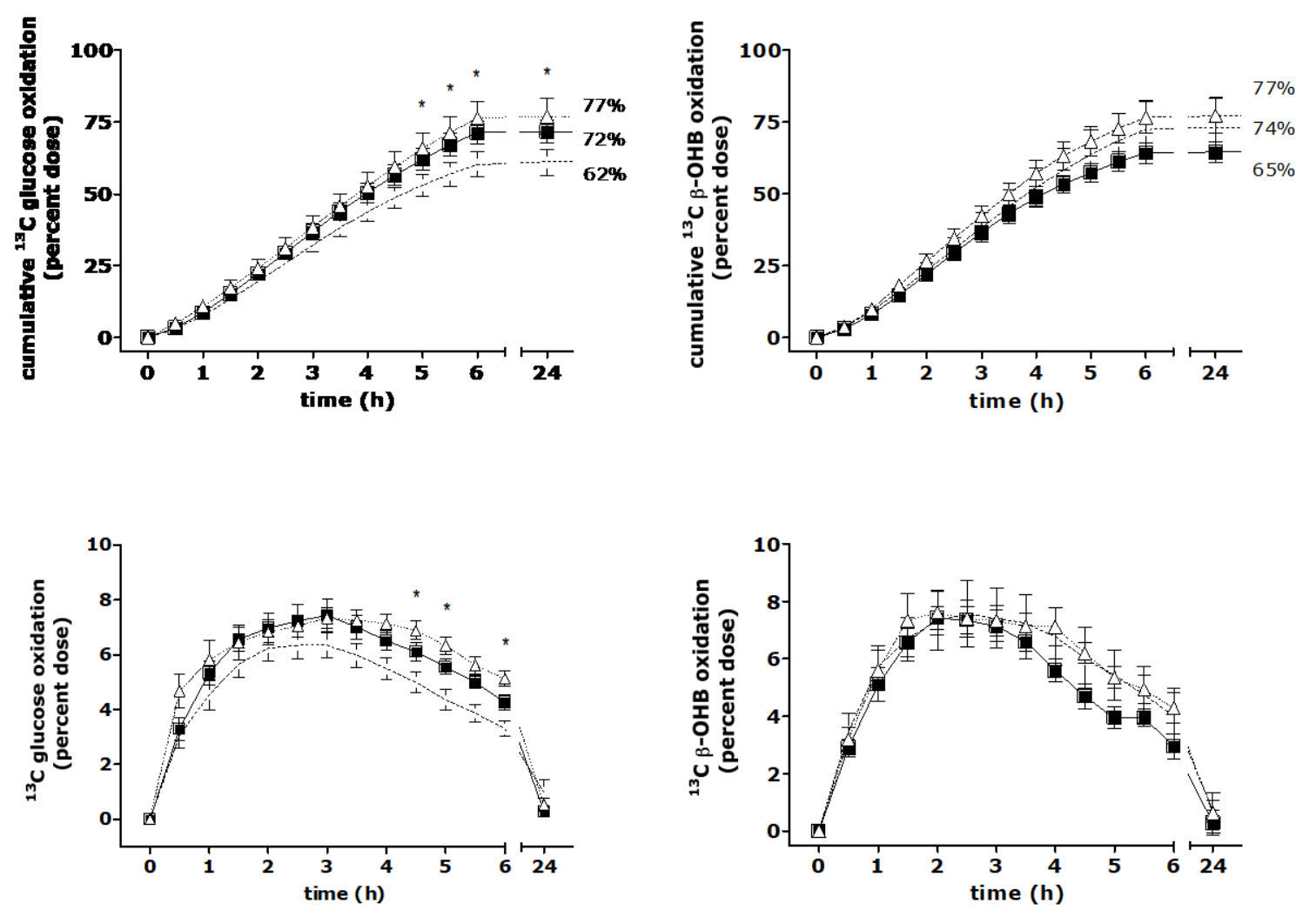

Figure 3. 

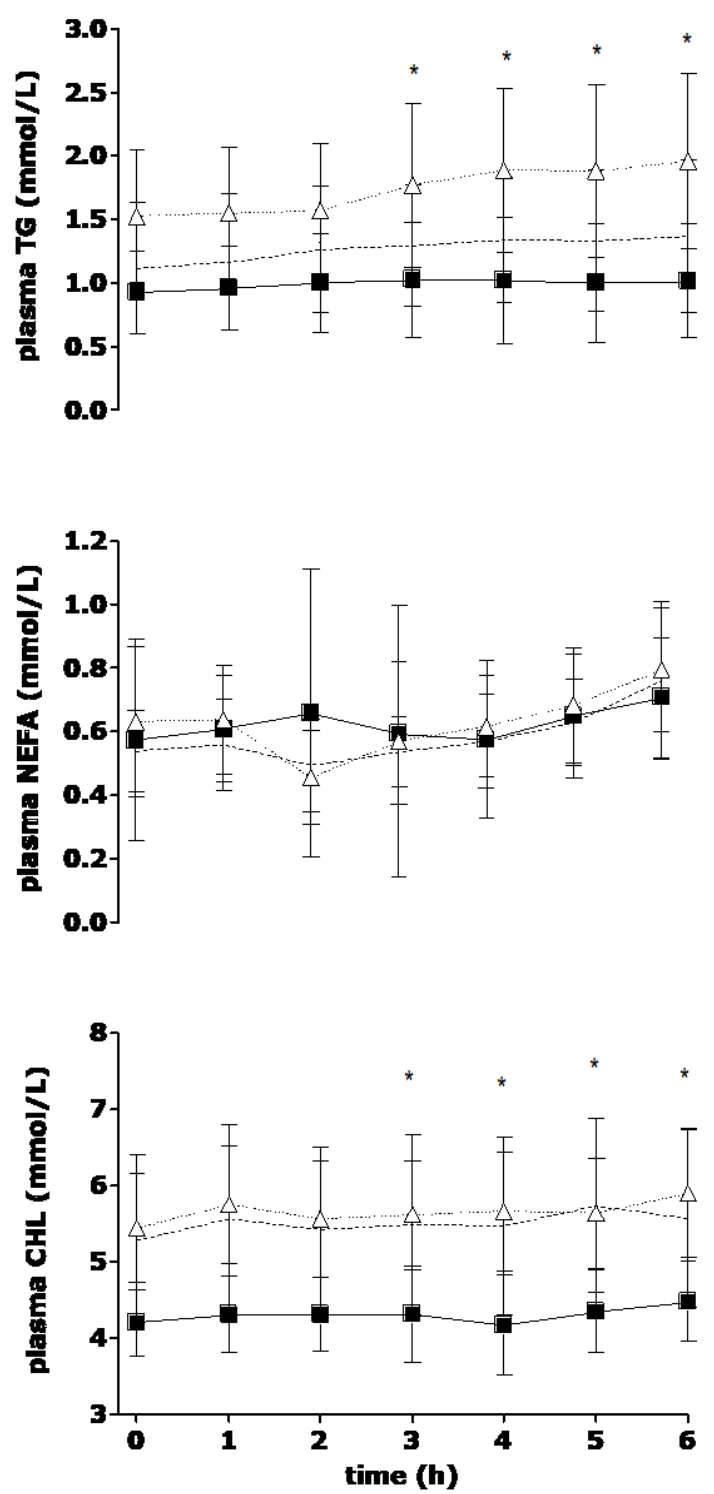

Figure 4. 


\section{Figure Legends}

\section{Figure 1.}

Plasma glucose (upper left), insulin (lower left), $\beta$-hydroxybutyrate (upper right), and breath acetone (lower right) over $6 \mathrm{~h}$ following consumption of a ketogenic breakfast at time 0 (mean $\pm \mathrm{SEM}$; $\left.{ }^{*}<<0.05\right)$. Symbols represent young $(\boldsymbol{\square})$, middle-aged $(\mathrm{O})$ and elderly $(\Delta)$ subjects.

\section{Figure 2.}

Correlation between breath acetone and plasma $\beta$-hydroxybutyrate before and $6 \mathrm{~h}$ after consuming a ketogenic breakfast.

\section{Figure 3.}

Oxidation of ${ }^{13} \mathrm{C}$ glucose (lower left - \% dose/h; upper left - cumulative oxidation/24 h) and ${ }^{13} \mathrm{C} \beta$-hydroxybutyrate (lower right - \% dose/h; upper right - cumulative oxidation/24 h) following consumption of a ketogenic breakfast and the respective tracer at time 0 (mean $\left.\pm S E M ;{ }^{*} P<0.05\right)$. Symbols represent young $(\boldsymbol{\square})$, middle-aged (O) and elderly $(\Delta)$ subjects.

\section{Figure 4.}

Plasma triacylglycerols (TG), non-esterified fatty acids (NEFA), and cholesterol (CHL) over $6 \mathrm{~h}$ following consumption of a ketogenic breakfast at time 0 . Symbols represent young $(\boldsymbol{\square})$, middle-aged $(O)$ and elderly $(\Delta)$ subjects (mean $\pm \mathrm{SEM}$; ${ }^{*} \mathrm{P}<0.05$ ). 
References (should be BEFORE the tables)

1. Sokoloff L. Measurement of local cerebral glucose utilization and its relation to local functional activity in the brain. Adv Exp Med Biol 1991;291:21-42.

2. Musa-Veloso K, Likhodii SS, Cunnane SC. Breath acetone is a reliable indicator of ketosis in adults consuming ketogenic meals. Am J Clin Nutr 2002;76:65-70.

3. Mitchell GA, Kassovska-Bratinova S, Boukaftane $Y$, et al. Medical aspects of ketone body metabolism. Clin Invest Med 1995;18:193-216.

4. Petersen KF, Befroy D, Dufour S, et al. Mitochondrial dysfunction in the elderly: possible role in insulin resistance. Science 2003;300:1140-2.

5. Freemantle E, Vandal M, Tremblay-Mercier J, et al. Omega-3 fatty acids, energy substrates, and brain function during aging. Prostaglandins Leukot Essent Fatty Acids 2006;75:213-20.

6. Reger MA, Henderson ST, Hale C, et al. Effects of beta-hydroxybutyrate on cognition in memory-impaired adults. Neurobiol Aging 2004;25:311-4.

7. Freund G, Weinsier RL. Standardized ketosis in man following medium chain triglyceride ingestion. Metabolism 1966;15:980-91.

8. Bach AC, Babayan VK. Medium-chain triglycerides: an update. Am J Clin Nutr 1982;36:950-62.

9. Weintraub MS, Eisenberg S, Breslow JL. Dietary fat clearance in normal subjects is regulated by genetic variation in apolipoprotein E. J Clin Invest 1987;80:1571-7.

10. Reiman EM, Chen K, Alexander GE, et al. Functional brain abnormalities in young adults at genetic risk for late-onset Alzheimer's dementia. Proc Natl Acad Sci USA 2004;101:284-9.

11. Poirier J. Apolipoprotein $\mathrm{E}$ in the brain and its role in Alzheimer's disease. $J$ Psychiatry Neurosci 1996;21:128-34.

12. Chevalier S, Gougeon R, Nayar K, Morais JA. Frailty amplifies the effects of aging on protein metabolism: role of protein intake. Am J Clin Nutr 2003;78:422-9.

13. Turner DL, Martin PA, Mitchell GS. Hypoxic exercise does not elicit long-term modulation of the normoxic exercise ventilatory response in Goats. Adv Exp Med Biol 1995;393:245-8.

14. McCloy U, Ryan MA, Pencharz PB, Ross RJ, Cunnane SC. A comparison of the metabolism of eighteen-carbon 13C-unsaturated fatty acids in healthy women. $J$ Lipid Res 2004;45:474-85. 
15. Whitehead R. New techniques in nutritional research. San Diego: Academic Press, 1991.

16. Schofield WN. Predicting basal metabolic rate, new standards and review of previous work. Hum Nutr Clin Nutr 1985;39 Suppl 1:5-41.

17. Slater C, Preston T, Weaver LT. Comparison of accuracy and precision of heart rate calibration methods to estimate total carbon dioxide production during 13Cbreath tests. Europ J Clin Nutr 2006;60:69-76.

18. Gehan EA, George SL. Estimation of human body surface area from height and weight. Cancer Chemother Rep 1970;54:225-35.

19. Nalbantoglu J, Gilfix BM, Bertrand P, et al. Predictive value of apolipoprotein E genotyping in Alzheimer's disease: results of an autopsy series and an analysis of several combined studies. Ann Neurol 1994;36:889-95.

20. Folch J, Lees M, Sloane Stanley GH. A simple method for the isolation and purification of total lipids from animal tissues. J Biol Chem 1957;226:497-509.

21. London ED, Margolin RA, Duara R, et al. Effects of fasting on ketone body concentrations in healthy men of different ages. J Gerontol 1986;41:599-604.

22. Issa JS, Diament J, Forti N. Postprandial lipemia: influence of aging. Arq Bras Cardiol 2005;85:15-9.

23. Zilversmit DB. Atherogenesis: a postprandial phenomenon. Circulation 1979;60:473-85.

24. Lewis GF, Carpentier A, Adeli K, Giacca A. Disordered fat storage and mobilization in the pathogenesis of insulin resistance and type 2 diabetes. Endocrine Rev 2002;23:201-29.

25. Boquist S, Hamsten A, Karpe F, Ruotolo G. Insulin and non-esterified fatty acid relations to alimentary lipaemia and plasma concentrations of postprandial triglyceride-rich lipoproteins in healthy middle-aged men. Diabetologia 2000;43:185-93.

26. Fulop T, Tessier D, Carpentier A. The metabolic syndrome. Pathol Biol (Paris) 2006;54:375-86.

27. Carpentier AC, Frisch F, Brassard P, et al. Mechanism of insulin-stimulated clearance of plasma nonesterified fatty acids in humans. Am J Physiol Endocrinol Metab 2007;292:E693-701.

28. Dallongeville J, Lussier-Cacan S, Davignon J. Modulation of plasma triglyceride levels by apoE phenotype: a meta-analysis. J Lipid Res 1992;33:447-54.

29. Seaton TB, Welle SL, Warenko MK, Campbell RG. Thermic effect of mediumchain and long-chain triglycerides in man. Am J Clin Nutr 1986;44:630-4. 
30. Hill JO, Peters JC, Swift LL, et al. Changes in blood lipids during six days of overfeeding with medium or long chain triglycerides. J Lipid Res 1990;31:407-16.

31. Boden G, Chen X, DeSantis RA, Kendrick Z. Effects of age and body fat on insulin resistance in healthy men. Diabetes Care 1993;16:728-33.

32. Boden G, Chen X, Desantis RA, Kendrick Z. Effects of insulin on fatty acid reesterification in healthy subjects. Diabetes 1993;42:1588-93. 